\title{
Optimization of flow distribution in flat plate solar thermal collectors with riser and header arrangements
}

\author{
Jorge Facão* \\ Solar Energy Laboratory, National Energy and Geology Laboratory (LNEG), Estrada do Paço do Lumiar, 22, 1649-038 Lisbon, Portugal
}

Received 6 June 2014; received in revised form 1 July 2015; accepted 20 July 2015

Available online 30 July 2015

Communicated by: Associate Editor Claudio Alejandro Estrada-Gasca

\begin{abstract}
The thermal performance of flat-plate solar collectors with riser and header arrangements is strongly influenced by the flow distribution through the absorber tubes. A more uniform flow distribution leads to a homogenous temperature distribution which gives higher collector efficiency. The $Z$ distribution usually has better performance when compared to $\Pi$ distribution. The design of the manifold influences the observed flow distribution. To optimize the manifold design, a correlation model was developed, based on correlations for minor pressure losses. Furthermore, the flow in this optimized geometry was simulated in 3D using the computational fluid dynamics (CFD) software code in order to confirm the results of the correlation based model. A new experimental low-intrusive technique was used to measure the flow distribution in an existing solar collector, validating the simulation results. The flow inside the absorber tubes is laminar; the major pressure loss inside riser tubes was measured using a high accuracy differential pressure transmitter, which then permits the indirect estimation of the mean velocity inside the tubes. It was the first time that this experimental methodology has been applied to analyse the flow distribution in solar collectors. The influence of the total water flow rate was analysed. For a good flow distribution it was concluded that the outlet header manifold should have a higher diameter compared to the inlet header diameter. Usually commercialised solar collectors have the headers with same diameter.
\end{abstract}

(C) 2015 Elsevier Ltd. All rights reserved.

Keywords: Flat-plate solar collector design; Flow distribution; CFD; Experimental; Optimization

\section{Introduction}

The thermal performance of flat-plate solar collectors with riser and header arrangements is strongly influenced by the flow distribution through the absorber tubes (Duffie and Beckman, 2006).

Investigations have conclusively showed that the collector efficiency can decrease by more than $20 \%$ if the uniformity of the flow distribution diminishes (Chiou, 1982). However, this result has not yet been validated experimentally.

\footnotetext{
* Tel.: +351 210924600; fax: +351 217163688 .

E-mail address: jorge.facao@lneg.pt
}

The nonuniform flow distribution in the collector panel will not only decrease the efficiency, but can also cause severe problems like water boiling in some parts of the collector. The boiling might cause flow oscillations due to evaporation and condensation (Fan et al., 2007). An uneven flow distribution increases also the pressure drop over the collector compared with an even distribution.

Wang and $\mathrm{Wu}(1990)$ have reported experimental results for flow distribution of several collectors associated in parallel. The flow in the absorber tubes could then be estimated from that results but it would be affected by a considerable uncertainty.

Weitbrecht et al. (2002) were the first to investigate experimentally the isothermal (without buoyancy effects) 